\title{
APUNTES DE DERECHO PROCESAL LABORAL
}

\author{
MARÍA EugENia MONTT RETAMALES* \\ Universidad de Chile
}

\section{ANTECEDENTES GENERALES}

El Foro para la Reforma Procesal Laboral, convocado en el año 2000 por el Gobierno de Chile, que concluyó con la dictación de las Leyes No 20.022 de 30 de mayo de 2005, modificada por la No 20.252 de 15 de febrero de 2008; No 20.023 de 31 de mayo de 2005 y No 22.087 de 3 de enero de 2006, modificada por la No 20.260 de 29 de marzo de 2008 y la No 20.287 de 17 de septiembre de 2008, sin perjuicio de otras modificaciones menores, permitió llegar al establecimiento de un Sistema Procesal Laboral que contempla procedimientos orales declarativos, de ejecución, de cobranza previsional y de recursos, ajustados a los más modernos sistemas imperantes internacionalmente y que han agilizado la solución de los conflictos, evitando la tensión de largas tramitaciones, aseveraciones que son reconocidas por todos los intervinientes en este campo del quehacer jurídico.

En una muy breve síntesis del contenido de los cuerpos legales citados, todos ellos incorporados en el Libro V del Código del Trabajo y en la Ley No 17.322 y D.L. 3.500, sobre cobro de cotizaciones previsionales, trataremos de entregar los aspectos más relevantes de estos nuevos procedimientos.

\section{LOS PRINCIPIOS QUE INFORMAN LOS PROCEDIMIENTOS ORALES LABORALES}

Podemos decir que los principios formativos del procedimiento son ideas matrices que dan a un conjunto de normas procesales características que las distinguen de otras, principalmente por la naturaleza de las normas sustantivas a las que sirven como instrumentos o herramientas útiles para que cumplan los efectos que el sistema les impone.

Es importante referirse, en primer lugar, a los principios que informan los nuevos procedimientos orales laborales, dada su importancia y reconocimiento normativo que presentan, lo que ha llevado, más allá de su reconocimiento, a su aplicación como fundamento de resoluciones judiciales.

También es importante señalar que el artículo 425 del Código del Trabajo señala que la oralidad, la publicidad y la concentración vendrían a constituir características o vías a través de las cuales se lleva adelante el desarrollo de los diferentes procedimientos que regula el Libro V de nuestro Código del Trabajo, no obstante, creemos que es preferible incorporar estas tres modalidades dentro de los principios a los cuales se les reconoce específicamente el carácter de tales.

Abogada. Profesora asistente, Facultad de Derecho, Universidad de Chile. 


\subsection{PRINCIPIO DE LA ORALIDAD}

Este principio establece que todas las actuaciones deben llevarse por las parte, en forma oral ante el tribunal de la causa. En forma inmediata, ordena que dichas actuaciones deben registrarse en su totalidad, a través de medios aptos que garanticen la fidelidad, conservación y reproducción de su contenido, señalando como medios válidos para ello la reproducción fonográfica, audiovisual o electrónica, pero se advierte que no solo debe registrarse todo lo actuado en la audiencia, sino que, además, la sentencia que se dicte fuera de ella.

No obstante lo dicho, encontramos que de dictarse sentencia fuera de audiencia en el procedimiento de aplicación general, tal como lo permite el artículo 457, no se ha contemplado una audiencia de lectura del fallo, sino que solo se cita a las partes para un día y hora en el cual se procederá a la notificación de la sentencia que se ha dictado en la causa.

Los actos procesales que constituyen excepción a la oralidad son la demanda, la contestación a la demanda, las actas que se levantan al término de cada una de las audiencias, preparatoria (art. 453 No 10) y de juicio (art. 455), los incidentes que pudieren promoverse fuera de audiencia (art. 443), la reposición que se dedujese fuera de audiencia (art. 475), el recurso de apelación que fuere procedente deducir fuera de audiencia y los recursos de nulidad y de unificación de jurisprudencia.

Finalmente es conveniente hacer presente que la oralidad representa la única vía factible para que el principio de la inmediación pueda cumplir el objetivo específico que le es propio, como se verá.

\subsection{PRINCIPIO DE LA PUBLICIDAD}

La publicidad, contemplada en el artículo 428, está establecida en forma imperativa por el legislador, lo que corresponde a la nueva tendencia en cuanto a que no existan procesos, o etapas del mismo, que tengan el carácter de secretos y que impidan la debida defensa de los intervinientes, no obstante lo dicho, creemos que excepcionalmente puede producirse una situación específica que requiera del tribunal la adopción de medidas que pudieren alterar este imperativo, especialmente si se trata de causas cuya publicidad pueda llevar a una vulneración de derechos o garantías fundamentales de, a lo menos, una de las partes. Nos referimos específicamente a casos de acoso sexual y el acoso laboral, incorporado este último, en forma reciente, como causal de terminación del contrato de trabajo.

\subsection{PRINCIPIO DE LA CONCENTRACIÓN}

De la concentración se ha dicho que es la economía procesal llevada al juicio. Por su parte, se ha definido el principio de la economía procesal como aquella vía que permite la resolución del conflicto con el menor desgaste de la Jurisdicción, por lo que, consecuentemente, la concentración permite que a través de una estructura procesal ágil, mediante el establecimiento de actuaciones, en las cuales se permita que se celebren actos procesales, en lo posible, en su totalidad y fijando plazos para ello, se resuelvan los conflictos entregados al tribunal para su resolución.

Este principio se encuentra reconocido en el artículo 428 y se manifiesta con toda sus fuerzas en otras disposiciones, como el artículo 426 que prohíbe la suspensión de las audiencias, señalando como única excepción el caso fortuito o fuerza mayor, debiendo 
decretarse la eventual suspensión mediante resolución fundada. La misma disposición establece que el tribunal deberá habilitar horarios especiales, para el caso que el desarrollo de la audiencia se hubiere extendido más allá del horario normal del tribunal.

\subsection{PRINCIPIO DE LA INMEDIACIÓN}

Este principio, en su aplicación y cumplimiento, nos da la garantía de que el contacto del juez con las partes y los medios de prueba que se rindan en la causa será directo, inmediato y sin intervención de ningún agente o elemento que impida esta relación.

La consagración positiva del principio se encuentra en el artículo 427, sin perjuicio de otras disposiciones en que se desprende lo imperativo de su aplicación. Esta disposición ordena que las audiencias se desarrollen en su totalidad ante el juez de la causa, debiendo interpretarse que se está refiriendo al juez competente del respectivo tribunal. En el mismo sentido, el artículo 460, pero ahora relacionando al juez que preside la audiencia de juicio con el que dicta sentencia, establece entre ambos un vínculo indisoluble, bajo sanción de tener que celebrarse nuevamente la audiencia en que se incorporarán las pruebas al juicio.

Otro ejemplo claro de lo referido, es lo dispuesto en el No 5 del artículo 454, que establece que los testigos podrán declarar únicamente ante el tribunal que conozca de la causa, exigencia que da cumplimiento al contacto directo ya indicado.

\subsection{PRINCIPIO DEL IMPULSO PROCESAL DE OFICIO}

Este principio, consagrado en el artículo 429, otorga al juez amplias y específicas facultades, con el objeto que lleve adelante el procedimiento respetando su estructura, procurando que se den los presupuestos establecidos por el legislador para la prosecución del mismo, impidiendo la realización de actuaciones dilatorias de las partes, evitando actuaciones que pudieren dar lugar a declaraciones de nulidad, dictando resoluciones que le permitan obtener las pruebas que lo lleven a la convicción que le permita resolver el asunto y desestimando todas aquellas que le soliciten y que solo persigan la realización de trámites innecesarios, corrigiendo los errores del procedimiento, entre otras.

El reconocimiento positivo de este principio lleva a dos importantes declaraciones que son consecuencia de las facultades entregadas al juez y que son la improcedencia del abandono del procedimiento en materia laboral y el impedimento de que solicite la nulidad la parte que ha originado el vicio en que lo funda o ha concurrido a su materialización, principio básico contemplado en el ordenamiento jurídico del derecho común, pero que requería una manifestación clara y específica en este procedimiento laboral.

\subsection{PRINCIPIO DE LA CELERIDAD}

Este principio contemplado en el artículo 428, aparece como la vía para que opere el principio de la concentración. En efecto, la indicada norma señala que los actos procesales, que serán públicos y concentrados, deberán realizarse con la celeridad necesaria, procurando concentrarse en un solo acto aquellas diligencias que sean posibles.

Clara manifestación de este imperativo legal se encuentra en lo dispuesto en el artículo 426, cuando ordena que las audiencias se celebrarán con las partes que asistan y que les afectarán todas las resoluciones que en ellas se dicten. El artículo 450, por su parte, estable- 
ce que el procedimiento de aplicación general se desarrollará en dos audiencias, la Audiencia Preparatoria y la Audiencia de Juicio, y entre ellas no podrá haber un plazo superior a 35 días hábiles.

\subsection{PRINCIPIO DE LA BUENA FE}

Este principio consagrado en el artículo 430 ordena que los actos procesales deberán ejecutarse de buena fe y para ello se faculta al tribunal para adoptar las medidas necesarias para impedir el fraude, la colusión, el abuso del derecho y las actuaciones dilatorias, las que define como aquellas que con el solo objeto de demorar la prosecución del juicio sean intentadas por alguna de las partes. Pero más bien aparece como un imperativo de que los actos procesales se ejecuten de buena fe, sin entregar fundamentos para conocer el concepto que correspondería en este ámbito procesal. Con todo, podemos recurrir a lo dispuesto en el artículo 1546 del Código Civil en donde se encuentra el principio básico que ordena que los contratos deben celebrarse de buena fe, lo que debe hacerse extensivo a cualquier tipo de acto jurídico, incluyendo los actos jurídicos procesales.

\subsection{PRINCIPIO DE LA BILATERALIDAD DE LA AUDIENCIA}

Este principio ha sido uno de los que han informado los procedimientos procesales modernos, incluyendo el procedimiento laboral y se puede conceptualizar diciendo que es aquel que garantiza que ninguna resolución judicial produzca efecto, sino a partir de la notificación de la misma, mediante la cual, la parte afectada por ella toma conocimiento de su contenido. Además, es bueno recordar que solo a partir de dicha notificación empiezan a correr los plazos, tanto para su cumplimiento, como para la impugnación de la referida resolución, en cuanto sea procedente.

Sin perjuicio de este efecto fundamental y protector para los litigantes, existe una excepción que cumple un objetivo que protege un bien superior a aquel que se podría considerar que estaría vulnerando. Nos referimos a las medidas cautelares que pueden ser concedidas sin notificación de la contraria, con el objeto de garantizar ya sea la entrada al proceso, la obtención de medios que constituyen antecedentes necesarios en la causa para su resolución o garanticen el cumplimiento efectivo de la obligación cuya satisfacción se busca.

Con todo, esta excepción solo opera en los casos específicamente autorizados por el sistema y deben ejercerse dentro y por los plazos específicamente establecidos (art. 444).

\subsection{PRINCIPIO DE LA GRATUIDAD}

Este principio, reconocido expresamente en el artículo 431, opera en el procedimiento laboral en dos aspectos diferentes. El primero se refiere a la gratuidad en el cumplimiento de actuaciones judiciales por parte de funcionarios especialmente designados para ello. Dicho funcionario es responsable de la estricta observancia en el cumplimiento de dicha gratuidad como de la diligencia misma.

El segundo aspecto que comprende la aplicación del principio, se refiere a la defensa gratuita que corresponde a quienes pueden gozar del llamado privilegio de pobreza, y para ello se fijan montos máximos de remuneraciones a percibir por quienes pueden acceder a este tipo de defensa la que, en nuestro nuevo sistema procesal laboral, se encuentra radicada 
en la Defensoría Laboral. Se agrega que dicha gratuidad se extiende a las actuaciones que les corresponda a los auxiliares de la administración de justicia, cuyo acceso lo garantiza expresamente, como también su oportuno cumplimiento.

\section{LAS REGLAS COMUNES A TODO PROCEDIMIENTO}

En esta materia podríamos decir que trataremos las reglas comunes a todo procedimiento, no obstante, cabe hacer una salvedad en lo que dice relación con la aplicación supletoria de las normas del Código de Procedimiento Civil, atendido que encontramos normas referente a ello, tanto en el párrafo del procedimiento de aplicación general, como en los procedimientos de ejecución y en el párrafo sobre recursos. Se aclarará lo dicho a continuación.

\subsection{Aplicación supletoria de las nORMas del Código del Procedimiento CIVIL \\ El párrafo $2^{\circ}$ que contiene las reglas comunes, comienza con el artículo 432 que se} refiere a la aplicación supletoria de las normas del Código de Procedimiento Civil, en el caso de no encontrarse en el código del ramo la regulación de una determinada actuación. De tener que recurrirse a disposiciones del indicado cuerpo procesal, hace procedentes las contempladas en los Libros I y II, pero advierte que ellas no serán aplicables en el caso que sean contrarias a los principios que informan el procedimiento laboral, en cuyo caso entrega al tribunal la responsabilidad de determinar la forma en que se practicará la actuación respectiva.

Como se ha dicho, la aplicación de las normas del cuerpo procesal civil las regula en relación con "este procedimiento", debiendo entenderse que se refiere al procedimiento de aplicación general que se contempla en el párrafo $3^{\circ}$, pero ello está subsanado con lo dispuesto por el inciso segundo de la misma disposición, que establece que las normas de dicho procedimiento de aplicación general se aplicarán supletoriamente en los procedimientos de tutela laboral y monitorio.

\subsection{LA COMPARECENCIA EN JUICIO}

En esta materia, el legislador no difiere en cuanto a las exigencias contenidas en la Ley No 18.120, ya que al tenor de lo dispuesto en el artículo 434, exige que se comparezca con patrocinio de abogado y representado con persona legalmente habilitada para actuar en juicio, lo que lleva a la conclusión que en las audiencias el abogado litigante puede estar asistido por el procurador de la causa, situación práctica que no se opone a la norma legal indicada y que respeta el imperativo legal del inciso final del artículo 431 que establece que las defensas orales solo podrán ser efectuadas por abogados habilitados.

\section{LOS PLAZOS}

Siguiendo la tendencia moderna en la materia, el código establece que todos los plazos que contempla este Libro son fatales, extinguiéndose por su sola ocurrencia la oportu- 
nidad de ejercer cualquier derecho o ejecutar algún acto procesal, excluyendo de esta regla solo a los plazos establecidos a favor del tribunal (Artículo 435).

En cuanto a los términos de días, estos son de días hábiles y no hace procedente el feriado judicial contemplado en el artículo 313 del Código Orgánico de Tribunales.

\section{LAS NOTIFICACIONES}

Esta materia está regulada desde el artículo 436 y hasta el artículo 442, contemplándose para el nuevo procedimiento laboral las notificaciones personal, especial laboral o por cédula laboral, por carta certificada y por el estado diario. Se incorpora la notificación por medios electrónicos o cualquier otro que solicite la parte, las que serán procedentes con la sola exclusión de la notificación de la demanda al demandado, la que debe producirse por los medios de aplicación general.

a) Notificación personal: es la procedente para la notificación de la demanda al demandado, la practica el funcionario que designe el tribunal, atendiendo las circunstancias del lugar en que funcione el tribunal y las demás consideraciones necesarias para la eficacia de la diligencia. Puede practicarse en cualquier día, entre las seis y las veintidós horas, en la morada o lugar donde pernocta el notificado, en su lugar de trabajo o en recintos de libre acceso al público, en los que todas las horas son hábiles y solo exigiendo que en este caso se procure causar la menor molestia al notificado. En caso de notificarse en días inhábiles, los plazos comenzarán a correr a las cero horas del día hábil inmediatamente siguiente.

b) Notificación especial laboral: es la personal que se convierte en tal cuando no es habido personalmente el demandado. En este caso, habiendo concurrido el ministro de fe a practicar la notificación, si en el domicilio indicado encuentra a persona adulta que manifiesta que ese es el que corresponde y que el notificado se encuentra en el lugar del juicio, de lo que deberá dejar constancia en la causa, procederá a hacer entrega de la demanda y de la providencia recaída en ella a dicha persona.

De no darse los presupuestos señalados, pero obteniendo igual información y cumpliendo la obligación de la constancia, podrá fijar en lugar visible un aviso que dé noticia de la demanda especificando las partes del juicio, materia de la causa, juez que conoce de ella y resoluciones que se notifican Si se tratare de un recinto habitacional en que no se permite acceso al público, la entrega de los antecedentes indicados se hará al conserje respectivo, debiendo dejar expresa constancia de este hecho.

En todos estos casos, deberá enviar carta certificada a las partes, el mismo día o al siguiente hábil, dando aviso de las notificaciones practicadas. La omisión de esta obligación no invalida la notificación, sino que solo hace responsable al funcionario de los daños y perjuicios que se originen, sin perjuicios de otras sanciones administrativas.

c) Notificación al trabajador demandado: el legislador se ha puesto en el caso que sea el trabajador a quien deba notificarse la demanda y para ello distingue si se hará en el lugar donde presta sus servicios y que corresponde al domicilio del demandante, en cuyo caso 
deberá, necesariamente, ser notificado en forma personal. Consecuencialmente las reglas precedentes solo operarán en el caso que sea notificado en su domicilio personal o en otro de los lugares señalados como hábiles para notificar, de conformidad con lo establecido en el artículo 436.

d) Notificación por aviso: es procedente tratándose de personas a notificar cuya individualización o domicilio sean difíciles de determinar o cuando la notificación se dificulta por el número de personas a notificar. En estos casos, de poca ocurrencia en materia laboral, se faculta la notificación mediante un aviso publicado, ya sea en el Diario Oficial, en cuyo caso es gratis para la parte trabajadora, o en un diario de circulación nacional o regional. Se exige un solo aviso, en cualquier día del mes, que contendrá un extracto de la demanda elaborado por el tribunal y copia íntegra de la resolución recaída en ella.

En el caso señalado, el legislador también faculta la notificación por cualquier medio idóneo que garantice el derecho a la defensa y los principios de igualdad y de bilateralidad de la audiencia.

En este último sentido se han conocido casos de notificaciones a través de carabineros o funcionarios de la Armada de Chile, tratándose de lugares muy apartados de recintos urbanos. Lo que es también de normal ocurrencia en regiones, es el llamado, vía programas de radio, para que las personas se presenten al tribunal para, ya sea notificarlos de una resolución o ponerlos en conocimiento de un situación especial y se sabe que las personas concurren y se practican las notificaciones requeridas.

e) Notificación por carta certificada: procede tratándose de la notificación de los testigos y para requerir la comparecencia personal de las partes y siempre que dicha citación no se haya practicado en las audiencias, por lo que se exige que en la primera actuación las partes señalen su domicilio, bajo el apercibimiento de ser notificadas dichas resoluciones por estado diario.

f) Notificación por el estado diario: corresponde a la notificación procedente para el resto de las resoluciones y en el caso indicado precedentemente. Se practican al tenor de lo dispuesto en el ordenamiento procesal civil. También opera en aquellos casos en que no se ha contemplado una forma especial de notificación, como sucede con la notificación de la sentencia que recae en los recursos de nulidad o de unificación de jurisprudencia.

g) Notificación por medios electrónicos: se trata de una notificación facultativa a la que se accede por petición de las partes, las que deben señalar su correo electrónico al tribunal. También se considera cualquier otro medio que la parte señale y, en ambos casos, deberá dejarse constancia de haberse practicado la notificación en la forma solicitada.

Es importante hacer presente que todas las notificaciones indicadas, personal, especial personal o especial por cédula, por aviso y por carta certificada, son sin costo para las partes, especialmente la que debe perfeccionarse por aviso, cuando se trata de la demanda del trabajador. 


\section{LOS INCIDENTES}

Los incidentes, eso es toda cuestión accesoria al juicio que requiere pronunciamiento del tribunal, están regulados en el artículo 443 del código y se trata de una estipulación muy simple que señala que deberán promoverse preferentemente en la audiencia respectiva y resolverse de inmediato, ordenando luego que el tribunal, excepcionalmente, podrá dejar su resolución para definitiva.

\section{LAS COSTAS}

El artículo 445 establece en forma imperativa la obligación del juez, al momento de dictar una resolución que ponga término a la causa o resuelva un incidente, el pronunciarse sobre el pago de las costas del procedimiento, tasando las procesales y regulando las personales, según corresponda.

Esta obligación ha venido a convertirse en un freno para el litigante activo que incidente innecesariamente durante el curso de las audiencias, ya que se expone a salir de ellas con una deuda a pagar dentro de quinto día, ya que la resolución que la impone solo sería susceptible del recurso de reposición y resuelto este en la audiencia, habría quedado la resolución ejecutoriada y a falta de pago dentro de quinto día, operará la ejecución de oficio del monto ordenado pagar (artículo 462).

\section{LOS NUEVOS PROCEDIMIENTOS ORALES LABORALES}

\subsection{PROCEDIMIENTO DE APLICACIÓN GENERAL}

Este procedimiento está contemplado a partir del artículo 446 que exige que la demanda deba contener una relación clara y circunstanciada de los antecedentes de hecho y de derecho en que se funda y las peticiones concretas que plantea al tribunal. Es la oportunidad que tiene, quien ejerce la acción, para hacer saber sus pretensiones y las argumentaciones que las respaldan. Lo mismo ocurre con la contestación de la demanda, la que, además, debe pronunciarse sobre todos los hechos contenidos en la demanda, aceptándolos o negándolos en forma expresa. El incumplimiento de esta exigencia lleva a la parte a enfrentar dos nuevos tipos de hechos que pudieren producirle efectos perniciosos para sus intereses. En efecto, para el caso de no contestar la demanda, o contestándola no referirse a hechos contenidos en ella, el juez al dictar la sentencia podrá tener dichos hechos como tácitamente admitidos. Por su parte, para el caso de allanarse o aceptar ciertos hechos, estos serán objeto de una sentencia parcial en la audiencia preparatoria, debiendo pagarse los montos que estén involucrados dentro del plazo de quinto día y, de no hacerlo, serán enviados de oficio a ejecución.

Conjuntamente con la contestación de la demanda, el demandado deberá oponer las excepciones que estime procedentes, todas conjuntamente, sin importar su naturaleza jurídica y deducir demanda reconvencional, de ser procedente, ya que se exige que mirada como demanda independiente sea de competencia del tribunal laboral y esté íntimamente ligada con la demanda que se contesta. 
Cabe hacer presente que el tribunal, al proveer la demanda, fija inmediatamente la fecha de la audiencia preparatoria para una fecha no posterior al día trigésimo quinto hábil posterior a la fecha de dicha providencia. La demanda debe notificarse a lo menos quince días hábiles antes de la celebración de la indicada audiencia y la contestación de la demanda debe presentarse, por escrito, con cinco días de antelación a la celebración de dicha audiencia.

La audiencia preparatoria, que se celebrará con las partes que asistan, afectándole a la que no lo hace todo lo que en dicha audiencia se realice y se resuelve, tiene por objeto concluir la etapa de discusión, evacuando los traslados que se concedan como consecuencia de las excepciones opuestas o de la demanda reconvencional deducida; resolver las excepciones que fueren procedentes al tenor de lo regulado en esa materia; llamar a las partes a conciliación, la que puede llegar a ser total o parcial y facultándose al tribunal para fijar las bases para su acuerdo; recibir la causa a prueba; resolver las impugnaciones que pudieren deducirse respecto de la resolución pertinente; conocer los medios de prueba que las partes ofrecerán para incorporar en la audiencia de juicio; decretar las pruebas que el tribunal estime procedentes y toda otra diligencia que fuere necesaria para proceder a la fijación de la audiencia de juicio, que es la de prueba propiamente tal. Al término de esta audiencia, el tribunal deberá fijar la audiencia de juicio, la que no podrá celebrarse más allá de treinta días hábiles contados desde la celebración de la preparatoria.

La audiencia de juicio, como se ha dicho, tiene por objeto la incorporación de las pruebas ofrecidas por las partes y las decretadas por el tribunal. Muy importante es la innovación en cuanto a que, tratándose de causas sobre despido, la parte demandada debe rendir la prueba en primer lugar, evitándose así la rendición inoficiosa de prueba por parte de la parte demandante, en caso de no haberse probado los hechos en que se fundó el despido, los que, por lo demás, son los únicos que la ley establece como los que deben probarse en la causa.

Las características más relevantes de los más importantes medios de prueba son: la documental debe impugnarse en las respectivas audiencias, a elección de la parte con derecho a hacerlo; la confesional solo procede por una sola vez, debiendo comparecer la parte y, para el caso que sea el demandado quien no comparezca y otorgue mandato a otra persona para hacerlo, esta última debe ser el gerente, el administrador, el capitán de barco o quien ejerce habitualmente funciones de dirección o administración por cuenta o representación de una persona natural o jurídica. En cuanto a la prueba testimonial, solo se admiten cuatro testigos por cada parte, los que no son susceptibles de inhabilitación y a los cuales examina tanto el tribunal como las partes. Los peritajes decretados y los oficios ordenados en la audiencia preparatoria deben estar a disposición del tribunal, a lo menos, con tres días de anticipación a la celebración de la audiencia de juicio. Tratándose de documentos que por ley debían estar en poder de la parte y no sean exhibidos sin causa justificada, habiéndolo decretado el tribunal, llevarán a que puedan estimarse como probadas las alegaciones hechas por la parte contraria en relación con la prueba decretada.

Con todo, el tribunal solo admite las pruebas que tengan relación directa con la controversia entregada para su resolución y que sean necesarias para emitir dicho pronunciamiento. La ley excluye de valor probatorio y señala que no pueden ser apreciadas por el tribunal, las pruebas que las partes aporten y que se hubieren obtenido directa o indirecta- 
mente mediante medios ilícitos o a través de actos que impliquen violación de los derechos fundamentales.

La audiencia de juicio tiene por objeto recibir la prueba ofrecida por las partes y, como ya se dijo, el magistrado que presida dicha audiencia deberá dictar sentencia, ya sea al término de la misma o dentro del plazo de décimo quinto día hábil contado desde su celebración. Concluye la indicada audiencia con el alegato final o de cierre, en el cual puede hacerse observaciones a la prueba rendida o demostrar al tribunal que la teoría del caso de la parte ha quedado acreditada con las pruebas rendidas por ella.

\subsection{PROCEDIMIENTO DE TUTELA LABORAL}

La acción que se ejerza se tramita bajo el procedimiento de aplicación general, pero tiene características especiales que lo distinguen y las más importantes son las siguientes:

a) Se aplica a cuestiones suscitadas en la relación laboral por aplicación de las normas que afecten los derechos fundamentales de los trabajadores consagrados en la Constitución Política de la República y que se indican específicamente en el artículo 485 del código. Se agregan a ellos los actos que vulneren el principio de no discriminación y los que vulneren la garantía de indemnidad, es decir, todos aquellos que resulten como consecuencia de represalias de la parte empleadora por el ejercicio de derechos que corresponden a la parte trabajadora.

b) También se aplica este procedimiento a las denuncias sobre prácticas antisindicales en que se incurra como consecuencia de las relaciones laborales.

c) Su tramitación goza de preferencia ante los tribunales laborales y ante las Cortes de Apelaciones, salvo cuando comprende, además, un reclamo por despido injustificado.

d) Dependiendo de los antecedentes que se hagan valer por la parte denunciante, el tribunal podrá dictar una primera resolución que ordene el cese inmediato del acto vulnerador de derechos fundamentales.

e) La denuncia podrá plantearla la parte trabajadora, las organizaciones sindicales e incluso las Inspecciones del Trabajo, cuando en el ejercicio de sus funciones, tomen conocimientos de actos que generen vulneración de derechos fundamentales.

f) Las Inspecciones del Trabajo siempre deberán emitir informes, a petición de los tribunales laborales.

g) Se contemplan sanciones pecuniarias de a lo menos seis meses de la última remuneración mensual devengada por el afectado y un máximo de once meses, sin tope en la base de cálculo.

h) Considera sanciones especiales tendientes a reparar los efectos de la vulneración de derechos, como pueden ser disculpas públicas al sujeto afectado, concurrencia a actividades de capacitación y otras tendientes a reparar las consecuencias de la vulneración de que hubiere sido objeto.

\subsection{PROCEDIMIENTO MONITORIO}

Este es un procedimiento aplicable a conflictos cuya cuantía no exceda del equivalente a diez ingresos mínimos mensuales y para las acciones que buscan la protección del fuero 
maternal. El primero se inicia en el ámbito administrativo, mediante un reclamo que debe plantear la parte trabajadora y que puede resolverse en el comparendo a que se cita por el inspector del trabajo actuante. En el caso de la acción que busca el restablecimiento de la protección del fuero maternal, se interpone directamente en los tribunales laborales.

Si no se genera acuerdo en el comparendo administrativo, la parte trabajadora deberá deducir demanda judicial, adjuntando a la misma toda la documentación que hizo valer en el ámbito administrativo, lo que facilita al tribunal laboral el ejercicio de la facultad que le otorga la ley, en cuanto a acoger la demanda y notificar a la parte contraria, tanto la demanda como la sentencia que la acoge. Notificada la parte demandada, tiene el plazo de diez días hábiles para reclamar de lo resuelto por el tribunal, en cuyo caso, este último procede a fijar, dentro de décimo quinto día, una audiencia única de contestación, conciliación y prueba, al término de la cual debe dictar sentencia. Como se puede concluir, se trata de una sentencia sujeta a la condición de que la parte contraria no reclame, dado que si lo hace, se fija la audiencia ya indicada.

Si el tribunal no estima procedente acoger la demanda, en forma inmediata procede a citar a las partes a la audiencia única de contestación, conciliación y prueba, debiendo dictar sentencia al término de la misma.

Este procedimiento también es aplicable a los reclamos por resoluciones administrativas, cuando la cuantía de la multa aplicada no excede el monto equivalente a los diez ingresos mínimos mensuales.

\subsection{PRocedimientos de EJECUCión}

En el párrafo correspondiente, el código regula tanto el procedimiento de cumplimiento de la sentencia y el procedimiento de ejecución de los otros títulos ejecutivos laborales.

La ejecución de la sentencia se genera de oficio por el tribunal declarativo, una vez que certifique que se encuentra ejecutoriada, remitiéndola al área respectiva del mismo tribunal o al tribunal de cobranza, para el caso que exista en su jurisdicción. En el caso del juicio ejecutivo laboral, es importante destacar que el legislador ha hecho una enumeración de los principales títulos ejecutivos, entre los que se encuentran los finiquitos, los instrumentos colectivos del trabajo y los acuerdos a que llegan las partes antes las Inspecciones del Trabajo, dejando abierta la posibilidad de otros a los cuales las leyes laborales o de seguridad social les confieran dicho mérito.

Podemos señalar que las principales características de ambos procedimientos son:

a) Las objeciones a la liquidación del crédito están limitadas a los errores de cálculo numérico, alteración de las bases de cálculo o elementos e incorrecta aplicación de los índices de reajustabilidad o de intereses emanados de los órganos competentes.

b) Frente a la ejecución, la parte ejecutada solo puede oponer las excepciones de pago de la deuda, remisión, novación y transacción, debiendo acompañar a dicha oposición los antecedentes que respalden sus alegaciones.

c) Se contempla una medida cautelar especial que se decreta de oficio por el tribunal o a petición de parte y que consiste en la retención por la Tesorería General de la República de los montos a devolver al ejecutado, por concepto de devolución de impuestos. 
d) Se faculta a las partes para suscribir un pacto para el pago del crédito, el que deberá contener los reajustes e intereses de los períodos de pago, estableciendo la cláusula de aceleración que hace que el no pago de una cuota lleva a que se tenga el total del crédito, como de plazo vencido.

e) Durante el curso de la tramitación de las ejecuciones indicadas, las resoluciones que se dicten son inapelables.

A falta de norma expresa, deben aplicarse supletoriamente las disposiciones del derecho procesal civil, pero debiendo fijarse por el tribunal consecuentemente con los principios propios de la judicatura laboral y teniendo como referencia las reglas de la ejecución civil, en lo que sean conciliables con dichos principios.

\section{LOS RECURSOS PROCESALES}

El párrafo quinto del Libro V del Código del Trabajo se refiere a los recursos de reposición, apelación, nulidad y unificación de jurisprudencia, excluyendo la aclaración, rectificación o enmienda, dado que el artículo 477 limita la impugnación de la sentencia definitiva solo al recurso de nulidad, lo que impide que se pretenda aclarar, rectificar o enmendar errores en que se hubiere incurrido en la dictación de la sentencia.

El recurso de reposición, regulado en el artículo 475, procede en contra de los autos, decretos y sentencias interlocutorias que no pongan término al juicio ni hagan imposible su continuación. Pueden deducirse en audiencias o fuera de ellas. En el primer caso se resolverán en el acto, pudiendo tramitarlas como incidentes. Cuando se deduzcan fuera de audiencia, podrán resolverse de plano o vía tramitación incidental. Se establece la situación especial en caso de que dentro del plazo para deducir un recurso de reposición se vaya a celebrar una audiencia, debiendo interponerse al inicio de la celebración de la audiencia de que se trate.

El recurso de apelación, contemplado en el artículo 476, puede deducirse en contra de las sentencias interlocutorias que pongan término al juicio o hagan imposible su continuación, las que se pronuncien sobre medidas cautelares y las que fijen el monto de las liquidaciones o reliquidaciones de beneficios de seguridad social.

Tratándose de sentencias definitivas, estas solo son impugnables a través del recurso de nulidad, el que se encuentra regulado a partir del artículo 477. Dicha disposición contempla la causal genérica del recurso y que se refiere a la infracción sustancial de los derechos o garantías constitucionales o cuando la sentencia ha sido dictada con infracción de ley que ha influido sustancialmente en lo dispositivo del fallo. El artículo 478 contempla el resto de las causales de nulidad, en sus diferentes aspectos, casi en forma específica, y en solo seis letras, de la a) a la f), contempla un número mayor de posibilidades de atacar un fallo, por darse los presupuestos contemplados por el legislador.

El referido recurso de nulidad puede requerir preparación, en el caso que el vicio que se alega haya tenido su génesis u origen durante la tramitación de la causa, en cuyo caso, debió haberse planteado la alegación pertinente en el momento oportuno. 
Debe deducirse dentro del plazo de diez días hábiles contados desde la notificación de la sentencia definitiva, por escrito, ante el tribunal que dictó la sentencia, el que, luego del examen de admisibilidad, lo envía al tribunal superior, ad quem para que lo conozca y resuelva. Puede fundarse en una o más causales de nulidad, las que deben hacerse valer, ya sea en forma conjunta o en forma subsidiaria, circunstancia de importancia para pasar el examen de admisibilidad del recurso. En su planteamiento debe indicarse el o los vicios en que se ha incurrido o la vulneración de los derechos o garantías constitucionales. Su interposición importa la suspensión de la ejecución de la resolución impugnada e impide la alegación de otras causales distintas a las ya alegadas.

Admitido a tramitación, se agrega a la tabla para el conocimiento del recurso, el que se conoce por la corte, solo mediante antecedentes generales y a través de los alegatos de las partes, los que no pueden exceder de 30 minutos. La corte tiene cinco días para fallar y la sentencia se notifica a las partes a través del estado diario de ese tribunal. Si se rechaza el recurso, solo se dicta la sentencia de nulidad. Por el contrario, si se acoge, deberá dictarse la sentencia de nulidad y la sentencia de reemplazo de aquella que se invalida.

Solo en forma excepcional, en contra de la sentencia que dicta el tribunal ad quem, procede el recurso de unificación de jurisprudencia, que busca establecer una jurisprudencia en materia de derecho uniforme para casos cuyos conflictos de fondo admitan una solución equivalente. Debe deducirse dentro del plazo de quince días hábiles, contados desde la notificación de la sentencia de nulidad, adjuntándose las sentencias, emanadas de tribunales superiores de justicia, en que apoya su petición. Admitido a tramitación el recurso, la parte contraria tiene el plazo de diez días hábiles para hacer valer sus derechos, lo que se traduce en hacer llegar a la Corte Suprema, que es el tribunal competente para conocer y fallar dicho recurso, los fallos que le permitan demostrar lo contrario. Su interposición no suspende el cumplimiento del fallo impugnado, por lo que se ha incorporado la institución de la fianza de resultas, es decir, debe ofrecerse garantía para el caso que se ejecute el fallo y, posteriormente, se falle en contra del recurrente que siguió adelante con la ejecución.

La sentencia que rechaza el recurso contiene la fundamentación del mismo, pero la que lo acoge debe dictar la sentencia que razona sobre esa decisión, luego debe dictar la sentencia que se hace cargo del recurso de nulidad impugnado y, finalmente, debe dictar la sentencia de reemplazo.

Esta ha sido una visión general del procedimiento laboral oral, sin entrar en los detalles que habrían dado lugar a un análisis crítico de las diferentes instituciones que intervienen y que han demostrado, durante el tiempo que lleva de aplicación, la necesidad de incorporar nuevas modificaciones a sus normas. 